\title{
FITOTECNIA
}

Artigo de Revisão

\section{BANCO DE SEMENTES DE PLANTAS DANINHAS E HERBICIDAS COMO FATOR DE SELEÇÃO ${ }^{(1)}$}

\author{
PATRÍCIA ANDRÉA MONQUERO ${ }^{(2)}$; PEDRO JACOB CHRISTOFFOLETI ${ }^{(3)}$
}

\begin{abstract}
RESUMO
O banco de sementes representa um papel ecológico importante no suprimento de novos indivíduos para as comunidades vegetais. Nos agroecossistemas, o banco de sementes, normalmente constitui um sério problema à atividade agrícola, pois garante infestações de plantas daninhas por longo tempo, mesmo quando é impedida a entrada de novas sementes na área. O solo agrícola é um grande depósito de sementes, entretanto, a composição florística de um solo, em determinado momento, não representa o potencial real de infestação, já que certas espécies necessitam de condições especiais para a quebra de dormência e posterior germinação. Além disso, as sementes que estão na superfície do solo também estão sujeitas à predação, parasitismo e dispersão. Os diferentes sistemas de manejo do solo e das culturas influenciam decisivamente na germinação e composição florística de uma área e, portanto, no banco de sementes do solo. Devido à seletividade intra e interespecifica, o uso contínuo de herbicidas com o mesmo mecanismo de ação, pode ocasionar mudanças na composição da comunidade de plantas daninhas selecionando espécies tolerantes ou biótipos resistentes ao controle.
\end{abstract}

Palavras-chave: dinâmica, germinação, herbicidas, seleção.

\section{ABSTRACT \\ WEED SEED BANK AND HERBICIDES AS SELECTION FACTOR}

The seed bank plays a very important ecological role in supplying new individuals to plant communities. In agro-ecosystems, seed banks normally present a serious problem to agricultural activity, as they guarantee weed infestation for a long period of time, even when the entry of new weed seeds into the area is prevented. Agricultural soil is a large seed deposit; however, the floristic composition of a soil at a certain moment does not represent the real infestation potential, as certain species need special conditions to break dormancy and to germinate. Furthermore, the seeds that are at the surface of the soil are also subjected to predation, parasitism and to being dispersed. Different systems of soil and crop management decisively influence the germination and floristic composition of an area and therefore, the soil seed bank. Due to intra and inter-specific selectivity, the continuous use of herbicides with the same action mechanism, they can cause changes in the composition of the weed community, selecting tolerant species or resistant biotypes to control.

Key words: dynamics, germination, herbicides, selection.

(1) Recebido para publicação em 5 de agosto e aceito em 10 de janeiro de 2005.

( $\left.{ }^{2}\right)$ Doutora em Agronomia, Área de concentração Fitotecnia, Departamento de Produção Vegetal, Universidade de São Paulo, Escola Superior de Agricultura "Luiz de Queiroz", Caixa Postal 9, 13418-900 Piracicaba (SP), Brasil. E-mail: pamonque@cca.ufscar.br

( $\left.{ }^{3}\right)$ Departamento de Produção Vegetal, Universidade de São Paulo, Escola Superior de Agricultura "Luiz de Queiroz", Piracicaba (SP), Brasil. 


\section{INTRODUÇÃO}

O termo banco de sementes tem sido adotado para designar as reservas de sementes viáveis no solo, em profundidade e na sua superfície (ROBERTs, 1981). SIMPSON et al. (1989) definem que o banco de sementes é constituído por sementes vivas, presentes no solo ou associadas a restos vegetais.

Normalmente, o tamanho do banco de sementes das plantas daninhas é, comparativamente, maior em áreas agrícolas do que em áreas não agrícolas de baixo distúrbio ambiental. Essa tendência é devido à estratégia dessas plantas de produzir grandes quantidades de sementes em ambientes que apresentem um alto distúrbio. DEUBER (1992) listou exemplos da elevada capacidade reprodutiva de algumas plantas daninhas: Amaranthus spp. (120.000 sementes/planta), Galinsoga parviflora (30.000 sementes/planta), Portulaca oleracea (53.000 sementes / planta). O número de flores e sementes de uma planta varia com as condições ambientais. Um estresse hídrico, por exemplo, pode acelerar o florescimento para garantir a perpetuação, porém haverá menor produção de flores e sementes. Muitas espécies de plantas daninhas se reproduzem por meio de partes vegetativas, como, por exemplo: Cyperus rotundus (rizomas, tubérculos e bulbos basais), Sorghum halepense (rizomas) e Cynodon dactylon (rizomas e estolhos). Há ainda, espécies como a Commelina benghalensis, que se reproduz através de sementes aéreas, sementes subterrâneas e fragmentos de caule.

Alguns pesquisadores estimaram que a quantidade de sementes enterradas na camada arável do solo em diferentes ecossistemas e localidades pode variar de 2.000 até 70.000 sementes por metro quadrado (JOHNSON e ANDERSON, 1986). Os bancos são espacialmente muito heterogêneos e há também variações na distribuição vertical das sementes no solo (Holub, 1994). Geralmente, os bancos de sementes são compostos por muitas espécies, mas, normalmente, as poucas espécies dominantes compreendem de $70 \%$ a 90\% do total (Wilson, 1988). Essas espécies, consideradas mais nocivas, são resistentes às medidas de controle e possuem capacidade de adaptação às diferentes condições edafoclimáticas. Existe um segundo grupo de sementes compreendendo de 10\% a 20\% do banco, que são espécies adaptadas à área geográfica. Um terceiro grupo é representado por uma pequena porcentagem de sementes recalcitrantes, com pequena longevidade, e por sementes introduzidas ou da própria cultura desenvolvida na área (WiLson et al., 1985).

As informações sobre os bancos de sementes de plantas daninhas no solo poderão ser uma ferramenta bastante importante na tomada de decisão sobre práticas de controle e manejo integrado de plantas daninhas. Modelos bioeconômicos como HERB (WILKERSON et al., 1991) e WEEDCAM (LYBECKER et al., 1991) utilizam as informações sobre a composição dos bancos de sementes para estimar as populações de plantas daninhas, as perdas de produtividade nas culturas devido à competição e para recomendar táticas de controle mais econômicas.

O objetivo desta revisão é abordar conceitos gerais sobre banco de sementes, dinâmica, dormência das sementes e sobre os herbicidas como fator de seleção.

\section{DISPERSÃO, GERMINAÇÃO E DORMÊNCIA}

\section{DAS SEMENTES DE PLANTAS DANINHAS}

A dispersão de diásporos pode ocorrer por meios próprios (autocoria) ou com o auxílio de agentes externos (alocoria). No primeiro caso, os frutos caem no solo ou se abrem liberando suas sementes. Existem, também, espécies que lançam suas sementes a distâncias relativamente grandes da planta-mãe, como Euphorbia heterophylla e Ricinus communis (BRIGHENTI, 2001).

No segundo caso, a dispersão é auxiliada por meios externos. Deuber (1992) listou os seguintes tipos de dispersão de sementes de plantas daninhas: hidrocoria (disseminação pela água), anemocoria (disseminação pelo vento); zoocoria (disseminação pelos animais); e antropocoria (disseminação pelo homem). O homem é um importante agente dispersor de sementes de plantas daninhas, seja diretamente, pela utilização de sementes ou mudas contaminadas, seja indiretamente como, por exemplo, através do uso de implementos ou sacarias que não foram suficientemente limpas e que podem distribuir sementes de plantas daninhas de uma área a outra.

A germinação das sementes é o resultado do balanço entre condições ambientais favoráveis e características intrínsecas das sementes, compreendendo uma seqüência ordenada de atividades metabólicas, que resulta na retomada do desenvolvimento do embrião, originando assim, uma plântula. As sementes viáveis e não dormentes germinam quando há disponibilidade de água, oxigênio, temperatura e em alguns casos luz (CASTRO e VIEIRA, 2001).

Dentre os fatores ambientais que influenciam a germinação, a disponibilidade de água é um dos mais importantes. A partir do momento que a semente absorve água, ocorre a reidratação dos tecidos com

Bragantia, Campinas, v.64, n.2, p.203-209, 2005 
conseqüente intensificação da respiração e de atividades metabólicas que geram a matéria e energia utilizada pelo embrião para a retomada de crescimento (CASTRO e VIEIRA, 2001).

A germinação só ocorre dentro de determinados limites de temperatura, que variam com as diferentes espécies. As altas temperaturas ocasionam desnaturação de proteínas com conseqüente perda da atividade enzimática, enquanto baixas temperaturas diminuem ou paralizam o metabolismo e, portanto, afetam a velocidade, porcentagem e uniformidade da germinação. Segundo Guo e Al-кнатів (2003), sementes de Amaranthus retroflexus e $A$. palmeri apresentaram picos de germinação quando expostas às temperaturas de 35/ $30{ }^{\circ} \mathrm{C}$ dia/noite, já as sementes de $A$. rudis germinaram melhor na temperatura de $25 / 20^{\circ} \mathrm{C}$ dia/noite.

De acordo com Castro e Vieira (2001), a germinação pode ser promovida ou inibida por exposição à luz branca. Assim, as sementes podem ser classificadas em: fotoblásticas positivas, que germinam melhor na presença de luz, fotoblásticas negativas, que germinam melhor na ausência de luz e fotoblásticas neutras que germinam com ou sem luz. A ação da luz vermelha $(660-760 \mathrm{~nm})$ leva o fitocromo da forma inativa (PV ou P660) à ativa (PVd ou P730), que liberaria ou ativaria as citocininas. Esse grupo de hormônio, agindo de maneira antagônica com relação aos inibidores da germinação, permite às giberelinas desempenhar varias funções no processo germinativo (Carvalho e NaKagawa, 1988).

As sementes de várias espécies de plantas daninhas são ortodoxas e, portanto, podem ser quiescentes se alguns dos fatores ambientais limitarem a germinação ou podem estar em estado de dormência (EGLEY, 1983).

Os diásporos das plantas daninhas podem ser dotados de mecanismos de dormência variáveis e de elevada longevidade. De acordo com Foley (2001), dormência é uma "falha" temporária na capacidade das sementes para germinar mesmo dispondo de todas as condições ambientais favoráveis. A dormência é influenciada por fatores genéticos e ambientais (Murdock e ElLIS, 1992). As sementes provenientes da mesma planta-mãe têm diferentes graus de dormência, dependendo das condições ambientais, época de desenvolvimento e posição da semente na inflorescência (DEKKER et al., 1996).

A dormência primária ou inata ocorre ainda na planta-mãe durante a formação e maturação da semente. Esse tipo de dormência é importante para muitas espécies, pois impede que as sementes germinem quando ainda estão ligadas às plantas-mãe.
A dormência secundária ocorre após a dispersão das sementes maduras, sendo induzida por fatores naturais ou artificiais (CHADOEUF-HANNEL, 1985). Geralmente, a dormência secundária é induzida quando são fornecidas às sementes todas as condições necessárias à sua germinação, exceto uma. Segundo Popiginis (1985), altas tensões de dióxido de carbono, por exemplo, podem causar dormência secundária em sementes de Brassica alba.

Segundo BRACCINI (2001) a dormência das sementes pode ser classificada de acordo com o mecanismo ou a localização do bloqueador ou inibidor, da seguinte maneira: embrião imaturo ou rudimentar, impermeabilidade do tegumento à água, impermeabilidade do tegumento ao oxigênio, restrições mecânicas, embrião dormente, dormência devido a inibidores internos e combinação de causas.

A dormência distribui a germinação ao longo do tempo, garantindo o potencial de regeneração do banco de sementes mesmo em condições ambientais adversas à sobrevivência das espécies e de perturbação contínua do solo para fins de cultivo (CARMONA, 1992). Algumas sementes para germinarem precisam passar por processos de superação (quebra) de dormência. Por exemplo, Oryza sativa e Avena fatua, normalmente, requerem temperaturas altas e secagem (Leopold et al., 1988). Ambrosia trifidia e Setaria viridis necessitam de baixas temperaturas e estratificação (BALLARD et al., 1996).

A longevidade das sementes no solo é variável em função da espécie, da profundidade de enterrio, do tipo de solo e das condições climáticas. BuRNSIDE et al. (1996) constataram que sementes de Setaria viridis, S. lutescens e S. primilia mantiveram a viabilidade por mais de dezessete anos quando enterradas a vinte centímetros de profundidade em cápsulas seladas.

DAWSON e BRUNs (1975) enterraram sementes de Setaria viridis, Setaria glauca e Echinochloa crus-galli em três diferentes profundidades $(2,5,10$ e $20 \mathrm{~cm})$ resgatando-as após três anos. Constataram que as sementes de todas estas espécies tiveram maior longevidade em função do aumento da profundidade de enterrio.

No caso do sistema de semeadura direta, onde há maior concentração de sementes na superfície do solo, ocorre um decréscimo do banco de sementes, devido à indução da germinação, perda de viabilidade ou predação e parasitismo. Yenish et al. (1992) observaram que sementes de Chenopodium album coletadas na superfície do solo, depois de instalado o sistema de plantio direto, germinaram $40 \%$ menos que as sementes coletadas a maiores profundidades após a aração. 


\section{DINÂMICA DO BANCO DE SEMENTES}

\section{DE PLANTAS DANINHAS}

O tamanho e a composição botânica das espécies que compõem uma população de sementes do solo, em dado momento, é o resultado do balanço entre a entrada de novas sementes e perdas por germinação, deterioração, parasitismo, predação e dispersão (CARMONA, 1992). Os principais meios de enriquecimento do banco de sementes são: produção de novas sementes por plantas remanescentes após controle e dispersão de sementes por meio de maquinários, animais, vento, água e o homem. $\mathrm{O}$ decréscimo do banco de sementes no solo varia em função da espécie, dormência, condições ambientais, presença de microrganismos e predadores, sendo a principal forma de decréscimo a germinação das sementes.

A germinação é bastante variável ao longo do tempo, ocorrendo fluxos de emergência das plantas daninhas em determinados períodos do ano. Esses fluxos são resultantes de condições ambientais favoráveis e da habilidade das sementes viáveis em responder a estes estímulos (CARMONA, 1992). As plantas daninhas anuais que ocorrem no verão, por exemplo, necessitam das baixas temperaturas do inverno para a quebra de dormência e posterior germinação durante a primavera. Por outro lado, as plantas anuais que ocorrem no inverno necessitam das altas temperaturas do verão anterior para estimular a germinação durante o outono.

Os bancos de sementes, em virtude do padrão de germinação e estabelecimento de plântulas foram classificados por THOMPSON e GRIME (1979) em transitórios e persistentes. No primeiro tipo, a germinação ocorre dentro do período de um ano após a dispersão e no segundo tipo, a ocorrência da germinação das sementes dispersas excede a esse período. As espécies de bancos transitórios não acumulam sementes no solo, sendo raras as espécies de plantas daninhas que fazem parte deste tipo de banco, dentre elas pode-se citar Avena fatua, Alopecurus myosuroides e Matricaria perflorata (BARRALIs et al., 1988). As espécies que formam o banco transitório estão adaptadas a explorar o espaço deixado por danos e morte da vegetação.

O tamanho e a composição do banco de sementes reflete todo o manejo adotado no controle de plantas daninhas na área. Uma redução desse banco pode significar menor problema com plantas daninhas nas áreas agrícolas e, portanto, economia para os agricultores, especialmente com herbicidas, além de ambiente mais saudável, com menor utilização de produtos químicos.

\section{METODOLOGIA PARA ESTUDO DO BANCO DE SEMENTES}

Uma predição precisa da emergência de plantas daninhas do banco de sementes permitiria aos agricultores um planejamento mais eficiente do controle e impediria a aplicação inadequada de herbicidas em condições de pré-emergência (CARDINA e Sparrow, 1996). A estimativa qualitativa e quantitativa das sementes no banco pode ser acompanhada pela germinação direta das amostras do solo ou extração física das sementes associada por ensaios de viabilidade (LUSCHEI et al., 1998).

A eficácia desses métodos tem sido objeto de muitos estudos (Roberts, 1981; Gross, 1990; CARdinA e Sparrow, 1996). Existem vários problemas relacionados com os métodos de estudo de banco de sementes das plantas daninhas. Dentre eles, destacase o número correto de amostragens do solo, métodos adequados para extração e separação das sementes das amostras do solo e cálculo da porcentagem de germinação dessas sementes.

Segundo BENOIT et al. (1989), a forma mais correta para se determinar o número ideal de amostras é pela relação de variância, na qual quanto maior o número de sementes em uma amostra por área, menor será a variância e o número de amostras necessárias para estimar o banco de sementes. Em função do objetivo da análise do banco de sementes o número de sementes pode ser alterado. Se a proposta de estudo for apenas a quantificação total de sementes, para se verificar o potencial de infestação de uma área, o número de amostras pode ser menor do que se o objetivo do estudo for de determinar alterações qualitativas e de evolução do banco de sementes em resposta a algum sistema de manejo (MEDEIROs, 2001). Os valores de diâmetro de amostradores citados na literatura encontram-se entre $2,5 \mathrm{~cm}$ (ROBERTS e NiELSON, 1981) e 4,5 cm (BARRALIS et al., 1988).

Com relação a profundidade recomenda-se trabalhar, em áreas cultivadas, nos primeiros $20 \mathrm{~cm}$ do perfil do solo, onde se pode encontrar $90 \%$ das sementes (BuHLER et al., 1997).

Para a quantificação do banco de sementes, um dos métodos mais utilizados é a enumeração da emergência de plantas a partir de amostras de solos colocadas em bandejas em casa de vegetação (Roberts, 1981).

BuHler e MAxwell (1993) aperfeiçoaram a separação física, que antes era somente feita através de peneiramento do solo, com a utilização de solução de alta densidade, utilizando o carbonato de potássio $\left(\mathrm{K}_{2} \mathrm{CO}_{3}\right)$, seguido de centrifugação. Nesse método há 
uma separação dos constituintes orgânicos do solo que são recolhidos para posterior identificação. Houve também a constatação que a exposição das sementes a 3,2 $\mathrm{M}$ de $\mathrm{K}_{2} \mathrm{CO}_{3}$ por períodos menores que 30 minutos não afeta a germinação das sementes. Porém em trabalhos posteriores, Luschei et al. (1998) verificaram que ao centrifugar as amostras na solução de carbonato de potássio, ocorreu uma redução da germinação de Setaria faberi de $94 \%$ para $52 \%$. Esse fato ocorre, pois as sementes são danificadas devido ao alto $\mathrm{pH}$ da solução em conjunto com o aumento da pressão hidrostática na centrifugação. Alguns autores sugerem a utilização de outros produtos químicos como o sulfato de magnésio $\left(\mathrm{MgSO}_{4}\right)$, conforme FREITAS (1990).

\section{HERBICIDAS COMO FATOR DE SELEÇÃO}

\section{DE ESPÉCIES DE PLANTAS DANINHAS}

Os herbicidas, quando utilizados por vários anos, podem permitir que certas espécies ou biótipos passem por seleção e se adaptem ao sistema de cultivo. Outros métodos de controle de plantas daninhas também podem exercer ação selecionadora como os meios mecânicos de controle que podem selecionar espécies de propagação vegetativa.

O emprego intensivo de herbicidas com mecanismos de ação similares pode selecionar espécies tolerantes ou biótipos resistentes. Do mesmo modo, herbicidas com efeitos residuais curtos podem selecionar espécies com germinação tardia. Segundo Wilson (1988), o uso repetitivo de herbicidas com o mesmo espectro de ação na cultura do arroz por quatro anos tem permitido a predominância de Eleocharis kuroguwae, Cyperus serotinus e Scirpus juncoides em supressão de plantas daninhas dicotiledôneas. FrYER et al. (1982) constataram que o uso contínuo do 2,4-D em áreas produtoras de cereais na Inglaterra aumentou a freqüência de plantas daninhas monocotiledôneas como Avena spp. e Alopecurus myosuroides, que não são controladas por este herbicida.

Algumas espécies de plantas daninhas têm sido relatadas como tolerantes às doses recomendadas do glyphosate, como por exemplo, Ambrosia artemisiifolia (KAPUSTA et al., 1994), Sesbania exaltatta, Ipomoea spp. (JorDAN et al., 1997; LicH et al., 1997). Na Argentina, PAPA et al. (2002), listaram as seguintes espécies de plantas daninhas tolerantes e que se tornaram problemas em áreas cultivadas por soja transgênica: Parietalia debilis, Petunia auxiliares, Verbena litoralis, Verbena bonariensis, Hybanthus parviflorus, Iresine difusa, Commelina erecta e Ipomoea spp.
No Brasil, a tolerância ao glyphosate tem sido detectada em algumas espécies de plantas daninhas, como Commelina benghalensis, Commelina diffusa (Durigan et al., 1988; SANTos et al., 2001), Ipomoea spp e Richardia brasiliensis (MONQUero, 2003).

Para prevenir a expansão de espécies de plantas daninhas tolerantes ao glyphosate, em áreas intensivamente tratadas com esse herbicida, como é o caso das áreas cultivadas por plantas transgênicas resistentes ao glyphosate e das áreas de plantio direto, recomendam-se medidas como a rotação de culturas e a mistura do herbicida glyphosate com outros diferentes mecanismos de ação (KRUSE et al., 2000). De acordo com Lich et al. (1997) várias misturas de glyphosate com outros herbicidas têm resultado em interações antagônicas e sinergísticas e que a mistura de glyphosate com os herbicidas bentazon ou fumiclorac resultou em respostas aditivas no controle de Abutilon theophrasti. As interações antagônicas são observadas mais freqüentemente quando se usam os herbicidas chlorimuron-ethyl, imazethapyr ou thifensulfuron em mistura com glyphosate. Pesquisas atestam que o uso de herbicidas inibidores da ALS, em mistura com herbicidas sistêmicos como o glyphosate, reduz o controle de algumas espécies de plantas daninhas (GERWICK et al., 1988).

Outra forma utilizada para o controle efetivo de plantas daninhas tolerantes ao glyphosate como Ipomoea grandifolia, Commelina benghalensis, Spermacocea latifolia é a aplicação seqüencial do herbicida glyphosate. Em 2002, no XXIII Congresso Brasileiro da Ciência das Plantas Daninhas, foram apresentados cerca de 16 trabalhos com a aplicação seqüencial do glyphosate, avaliando o efeito sobre algumas plantas daninhas e sobre culturas transgênicas. Nas áreas de soja transgênicas do sul dos Estados Unidos, segundo NorsWORTHY et al. (2002), essa estratégia já é uma rotina e, normalmente, a primeira aplicação ocorre quando as plantas daninhas estão com 10-20 cm de altura e a segunda, entre 15 e 20 dias após a primeira.

Além do controle mecânico convencional, outras estratégias não químicas também devem ser consideradas no manejo de plantas daninhas. A rotação de culturas, particularmente daquelas com diferentes ciclos de vida, reduz o sucesso intrínseco das plantas daninhas que estão sincronizadas com a cultura, implicando na variação dos padrões de uso do solo e da interferência das plantas daninhas. Técnicas que reduzem o banco de sementes de plantas daninhas podem ser utilizadas tais como: pastagem ou produção de forrageiras, períodos de pousio utilizando herbicidas não-seletivos, utilização de adubos verdes, queima de resíduos da cultura ou de plantas daninhas após a colheita (Powles e Holtum, 1994). 


\section{REFERÊNCIAS}

BALLARD, T.O.; BAUMAN, T.T.; FOLEY, M.E. Germination viability and protein changes during stratification of giant ragweed seed. Journal of Plant Physiology, Stuttgart, v.149, n.1/2, p.229-232, 1996.

BARRALIS, G.; CHADOEUF, R.; LOCHAMP, J.P. Longevité des semences des mauvaises herbes annuelles dans un sol cultivé. Weed Research, Oxford, v.28, p.407-417, 1988.

BENOIT, D.L.; KENKEL, N.C.; CARVERS, P.B. Factors influencing the precision of soil seed bank estimates. Canadian Journal of Botany, Ottawa, v.67, n.10, p.2833-2840, 1989.

BRACCINI, A. L. Banco de sementes e mecanismos de dormência em sementes de plantas daninhas. In: OLIVEIRA JÚNIOR, R.S.; CONSTANTIN, J. (Eds.). Plantas daninhas e seu manejo. Guaíba: Agropecuária, 2001. p.59-102.

BRIGHENTI, A.M. Biologia de plantas daninhas. In: OLIVEIRA JÚNIOR, R.S.; CONSTANTIN, J. (Eds.). Plantas daninhas e seu manejo. Guaíba: Agropecuária, 2001. p.18-58.

BUHLER, D.D.; HARTZLER, R.G.; FORCELLA, F. Implications of weed seed bank dynamics to weed management. Weed Science, Champaign, v.45, n.3, p.329-336, 1997.

BUHLER, D.D.; MAXWELL, B.D. Seed separation and enumeration from soil using $\mathrm{K}_{2} \mathrm{CO}_{3}$ centrifugation and image analysis. Weed Science, Champaign, v.41, n.2, p.298-302, 1993.

BURNSIDE, O.C.; MOOMAW. R.S.; ROETH, F.W.; WICKS, G.A.; WILSON, R.G. Weed seed demise in soil in weed-free corn (Zea mays) production across Nebraska. Weed Science, Champaign, v.34, n.2, p.248-251, 1996.

CARMONA, R. Problemática e manejo de banco de sementes de invasoras em solos agrícolas. Planta Daninha, Brasília, v.10, n.1/2, p.5-16, 1992.

CARDINA, J.; SPARROW, D.H. A comparison of methods to predict weed seedling populations from the soil seedbank. Weed Science, Champaign, v.44, n.1, p.46-51, 1996.

CARVALHO, N.M.; NAKAGAWA, J. Dormência de sementes: ciência, tecnologia e produção. 3 ed. Campinas: Fundação Cargill, 1988, p. 129-174.

CASTRO, P.R.C.; VIEIRA, E.L. Aplicações de reguladores vegetais na agricultura tropical. Guaíba: Agropecuária, 2001. 132p.

CHADOEUF-HANNEL, R. La dormance chez les semences des mauvaises herbs. Agronomie, Paris, v.5, p.761-772, 1985.

CONGRESSO BRASILEIRO DA CIÊNCIA DAS PLANTAS DANINHAS, 23., Gramado, 2002. Resumos... Gramado: SBCPD, 2002. 718p.

DAWSON, J.H.; BRUNS, V.F. Longevity of barnyardgrass, green foxtail and yellow foxtail seeds in soil. Weed Science, Champaign, v.23, n.5, p.437-440, 1975.
DEKKER, J.; DEKKER, B.I.; HILHORST, H.; KARSSEN, C. Weed adaptation in Setaria spp. IV. Changes in the germinative capacity of S. faberi (Poaceae) embryos with development from anthesis to after abscission. American Journal of Botany, Columbus, v.83, n.8, p.979-991, 1996.

DEUBER, R. Botânica das plantas daninhas. In: DEUBER, R. Ciência das Plantas Daninhas. Jaboticabal: FUNEP, 1992. cap.2, p.31-73.

DURIGAN, J.C.; GALLI, A.J.B.; LEITE, G.J. Avaliação da eficiência da mistura de glyphosate e 2,4-D para o controle de plantas daninhas em citros. In: CONGRESSO BRASILEIRO DE HERBICIDAS E PLANTAS DANINHAS, 17, 1988, Piracicaba. Resumos... Piracicaba: Sociedade Brasileira de Herbicidas e Plantas Daninhas, 1988. p.303-304.

EGLEY, G.H. Seed germination in soil: dormancy cycles. In: KIGEL. J.; GALILI, G. (Eds.). Seed development and germination. New York: Marcel Dekker, 1995. p. 529-543.

FOLEY, M.E. Seed dormancy: an update on terminology, physiological genetics, and quantitative trait loci regulating germinability. Weed Science, Lawrence, v.49, n.3, p.305-317, 2001.

FREITAS, R.R. Dinâmica do banco de sementes em uma comunidade de plantas daninhas com aspectos de germinação e dormência de sementes de capim marmelada. 1990. 188f. Tese (Doutorado) - Escola Superior de Agricultura de Lavras.

FRYER, J.D.; SMITH, P.D.; LUDWIG, J.W. Long term persistence of picloran in a sandy loam soil. Journal of Environment Quality, Madison, v.8, n.1, p.83-85, 1982.

GERWICK, B.C.; THOMPSON, P.; NOVEROSKE, R. Potential mechanisms in antagonism with aryloxyphenoxypropionate herbicides. Proceedings of Weed Science, Minneapolis, v.28, p.100, 1988.

GROSS, K.L. A comparison of methods for estimating seed numbers in the soil. Journal of Ecology, Oxford, v.78, n.4, p.1079-1093, 1990.

GUO, P.; AL-KHATIB, K. Temperature effects on germination and growth of redroot pigweed (Amaranthus retroflexus), palmer amaranth (A. palmeri), and common water hemp (A. rudis). Weed Science, Lawrence, v.51, n.6, p.869-875, 2003.

HOLUB, M. Vertical structure of the soil seed bank below wheat, sugar beet and lucerne. Biologia Bratislava, Brastilava, v.49, n.1, p.53-57,1994.

JOHNSON, R.G.; ANDERSON, R.C. The seed bank of tall grass prairie in Illinois. American Midland Naturalist, Notre Dame, v.115, p.123-130, 1986

JORDAN, D.L.; YORK, A.C.; GRIFFIN, J.L.; CLAY, P.A.; VIDRINE, P.R.; REYNOLDS, D. B. Influence of application variables on efficacy of glyphosate. Weed Technology, Champaign, v.11, n.2, p.354-362, 1997.

KAPUSTA, G.; KRAUZ, R. F.; MATTHEWS, J. L. Annual weed control with glyphosate at several rates, weed sizes and spray volumes. Proceedings of Northeast Weed Science Society, Champaign, v.49, p.120-121, 1994. 
KRUSE, N.D.; TRESSI, M.M.; VIDAL, R.A. Herbicidas inibidores da EPSPs: revisão de literatura. Revista Brasileira de Herbicidas, Brasília, n.1, v.2, p.139-146, 2000.

LEOPOLD, A.C.; GLENIST. R.; COHN, M.A. Relationship between water content and after ripening in red rice. Physiologia Plantarum, Copenhagen, v.74, n.4, p.659-662, 1998.

LYBECKER, D.W.; SCHWEIZER, E.E.; KING, R.P. Weed management decisions in corn based on bioeconomic modelling. Weed Science, Champaign, v.39, n.1, p.124-129, 1991.

LICH, J. M.; RENNER, K. A.; PENNER, D. Interaction of glyphosate with postemergence soybeans (Glycine max) herbicides. Weed Science, Champaign, v.45, n.1, p.12-21, 1997.

LUSCHEI, E.C.; BUHLER, D.D.; DEKKER, J.H. Effect of separating giant foxtail (Setaria faberi) seeds from soil using potassium carbonate and centrifugation on viability and germination. Weed Science, Champaign, v.46, n.5, p.545548,1998

LYBECKER, D.W.; SCHWEIZER, E.E.; KING, R.P. Weed management decisions in corn based on bioeconomic modelling. Weed Science, Champaign, v.39, n.1, p.124-129, 1991.

MEDEIROS, D. Efeito da palha de cana-de-açúcar sobre o manejo de plantas daninhas e dinâmica do banco de sementes. 2001, 125f.. Dissertação (Mestrado) - Escola Superior de Agricultura Luiz de Queiroz, Piracicaba.

MONQUERO, P.A. Dinâmica populacional e mecanismos de tolerância de espécies de plantas daninhas ao herbicida glyphosate. 2003, 99f. Tese (Doutorado) - Escola Superior de Agricultura "Luiz de Queiroz", Piracicaba.

MURDOCK, A.J.; ELLIS, R.H. Longevity, viability and dormancy. In: FENNER, M (Ed.). Seeds: the ecology of regeneration in plant communities. Wallingford: $C A B$ International, 1992. p.193-229.

NORSWORTHY, J.K.; BURGOS, N.R.; OLIVER, L.R. Differences in weed tolerance to glyphosate involve different mechanism. Weed Technology, Lawrence, v.15, n.4, p.725-731, 2001.

PAPA, J.C.M.; FELIZIA, J.C.; ESTEBAN, A.J. Cambios en la flora de malezas como consecuencia del cambio tecnologico en Argentina: malezas novedosas que pueden afectar al cultivo de la soja. In: CONGRESSO BRASILEIRO DE SOJA E MERCOSOJA, 2., Foz do Iguaçu, 2002. Anais... Foz do Iguaçu: EMBRAPA, 2002. p.346-354.
POPIGINIS, F. Fisiologia da semente. 2 ed. Brasília: s.ed., 1985. 289p.

POWLES, S.B.; HOLTUM, J.A.M. Herbicide resistance in plants: biology and biochemistry. Boca Raton, FL: CRC Press, 1994, 353p.

ROBERTS, H.A. Seed banks in the soil. In: ROBERTS, H.A. (Ed.). Advances in Applied Biology. Cambridge: Academic Press, 1981. v.6, p.1-55.

ROBERTS, H.A.; NIELSON, J.E. Changes in the soil seed bank of four long term crop herbicide experiments. Journal of Applied Ecology, Oxford, v.18, p.661-668, 1981.

SANTOS, I.C.; SILVA, A.A.; FERREIRA, F.A.; MIRANDA, G.V.; PINHEIRO, R.A.N. Eficiência de glyphosate no controle de Commelina benghalensis e Commelina diffusa. Planta Daninha, Viçosa, v.19, n.1, p.135-143, 2001.

SIMPSON, R.L.; LECK, M.A.; PARKER, V.T. Seed banks: General concepts and methodological issues. In: LECK, M.A.; PARKER, V.T.;SIMPSON, R.L. (Eds.). Ecology of soil seed banks. London: Academic Press, 1989. p.3-8.

THOMPSON, K.; GRIME, J.P. Seasonal variation in the seed banks of herbaceous species in ten contrasting habitats. Journal of Ecology, Oxford, v.67, n.3, p.893-921, 1979.

WILKERSON, G.G.; MODENA, S.A.; COBLE, H.D. Herb: decision model for post emergence weed control in soybean. Agronomy Journal, Madison, v.83, n.2, p.413-417, 1991.

WILSON, R.G.; KERR, E.D.; NELSON, L.A. Potential for using weed seed content in the soil to predict future weed problems. Weed Science, Champaign, v.33, n.2, p.171-175, 1985.

WILSON, R.G. Biology of weed seed in the soil. In: ALTIERI, M.L.; LIEBEMAN, M. (Ed.). Weed Management in Agroecosystem: Ecological Approaches. Boca Raton, Florida: CRC Press, 1988, p.25-39.

YENISH, J.P.; DOLL, J.D.; BUHLER, D.D. Effects of tillage on vertical distribution and viability of weed seed in soil. Weed Science, Champaign, v.40, n.3, p.429-433, 1992. 